\title{
The carbon impact of flying to economics conferences: Is flying more associated with more citations?
}

\author{
Konstantinos Chalvatzis ${ }^{\mathrm{a}}$, Peter L Ormosi ${ }^{\mathrm{a}, \mathrm{b} 1}$ \\ ${ }^{a}$ Norwich Business School, University of East Anglia, Norwich NR4 7TJ, UK \\ ${ }^{\mathrm{b}}$ Centre for Competition Policy, University of East Anglia, Norwich NR4 7TJ, UK
}

August 27, 2020

\begin{abstract}
An increasing body of literature has highlighted the significant carbon impact of academic conferences. Our paper further adds to this growing body of evidence by introducing a newly assembled dataset from a sample of 263 economics conferences, including 55,006 presentations by 26,312 academics. First, we offer a detailed description of the travelling pattern of academics presenting their work at these conferences, and highlight the main differences between academics and institutions in different geographical regions. Academic conferences are intuitively linked to increased dissemination in the expectation that they boost various impact metrics. For this reason we look at the relative role of the distance travelled and the number of trips made to present each paper in driving the number of citations these papers receive. We present evidence that the number of trips matters for more citations but longer distances are only associated with higher citation numbers for European academics. The potential reasons behind this heterogeneity are discussed in detail. Our results offer support to recent evidence showing that higher carbon impact is not necessarily associated with enhanced academic outcomes.
\end{abstract}

Key words: carbon-impact, flying, academic conferences, economics

\footnotetext{
${ }^{1}$ Corresponding author: Peter L Ormosi, email: p.ormosi@uea.ac.uk

†Special thanks to Farasat Bokhari, Franco Mariuzzo and three anonymous referees for their helpful suggestions on this paper. The full dataset and the Python code used for the Tables and Figures in the paper are available here: https://github.com/PeterOrmosi/conference_carbon_ impact_economics
} 


\section{Introduction}

Universities have been active in reducing the carbon impact of academia. However, conference travelling has so far largely escaped serious changes in attitude, especially in social sciences. ${ }^{2}$ The scarcity of action is not surprising; conferences are a defining part of academic research. Attending conferences carries multiple benefits. It can spur collaborative works (Wang et al., 2017), contribute to networking (Elliott and Urry, 2010), (Storme et al., 2013), improve promotion chances, and help remain visible (Storme et al., 2013), (Storme et al., 2017). In some disciplines full international conference proceedings are presented, peer-reviewed, and published. Moreover, internationally collaborative papers are cited more frequently (Adams, 2013), and physical proximity and the direct diffusion of knowledge are particularly important in knowledge-generating institutions (Cantwell and Mudambi, 2011), (Edler et al., 2011), (Denstadli et al., 2012). Travelling to academic conferences is therefore typically viewed a cardinal and indispensable part of academic life (Storme et al., 2013).

Perceptions that flying is necessary from a societal or individual perspective poses a significant challenge to efforts aimed at reducing carbon emissions (Gössling et al., 2019). If flying to conferences is regarded as an inevitable part of academic advancement (Adams, 2013), this perception can become an important barrier to reducing the carbon impact of academia. Changing these perceptions would be an important step in altering academic travelling behaviour.

There is an increasing body of literature, which is more sceptical about the net benefit of attending conferences - particularly highlighting their carbon impact. Burke (2010), and Fox et al. (2009) offered an early assessment, and Green (2008) was one of the firsts to provide back of the envelope calibrations to highlight the carbon impact of these conferences. These have been followed by more detailed, and data-driven research, for example looking at the impact of researchers' seniority, or flight preferences (first or second class) on their carbon footprint (Ciers et al., 2019), the non-flying related carbon impact of conferences (Achten et al., 2013), or the impact of specific conferences (Desiere, 2016), (Nevins, 2014), or specific institutions (Arsenault et al., 2019). There have also been studies that focused more on the distances travelled, such as Spinellis and Louridas (2013) and Wynes et al. (2019). From a different perspective, other authors looked at the credibility of climate researchers with large carbon footprints, using survey evidence Attari et al. (2016), and the environmental policies (such as carbon-offsetting policies) of academic con-

\footnotetext{
${ }^{2}$ Although some universities started flagship initiatives, such as 'Flying Less Policy' at the Concordia University in Montreal, https://www. concordia.ca/content/dam/artsci/geography-planning-environment/docs/Flying_Less_Policy_GPE_June1_2019.pdf
} 
ferences (Holden et al., 2017). Solutions that help reduce carbon emissions without jeopardising these benefits have also been proposed, such as virtual conferences, or presenting papers at local, rather than far-away venues. We review these proposals in our final section on potential solutions.

The first contribution of this paper to the existing literature is that we look at a novel dataset of conferencerelated travel data, using a sample of 263 economics conferences, and calculate their carbon impact to help us get a grasp of the magnitude of the environmental costs of these events. Using this travel information, as its main contribution, the paper investigates the relationship between conference presentations and the distances travelled, and academic citations. We offer evidence that presenting at far-away conferences is typically not associated with higher citations (whether or not we control for the academic stature of the speaker). One exception is European academics, whose citation figures seem to profit from cross-Atlantic trips. We interpret this as support in favour of the argument for more localised conferences.

In passing, the paper offers a number of alarming statistics that we hope economics departments around the world will find equally concerning. Alone in our small sample, people travelled over 72 million kms to present works, to which we found that there was zero subsequent citations, and a further 80 million $\mathrm{kms}$ to present papers that later received 5 or fewer citations. Academic conferences undoubtedly deliver a multitude of benefits, but one could reasonably be concerned if those benefits do not manifest in at least a moderate increase in citation metrics.

This is not the first paper to look at the carbon impact of economists in academia. Balmford et al. (2017) compared the carbon footprint and behaviour of a sample of economists to a matching sample of conservationists and medics, and found that carbon footprint is unrelated to environmental knowledge, although overall footprint size was higher among economists. Our secondary research question on the relative relationship between citation numbers and conference trips/distances has also been looked at in earlier works. Wynes et al. (2019), a paper that is most relevant to our own, found no relationship between citation numbers and travelling activity. Wynes et al. (2019) focuses on the travelling records of a specific institution (University of British Columbia) to look at the relationship between air travel intensity and bibliometric output. The authors had detailed records for 1769 trips taken by 997 individual travellers. For their sample they found no correlation between academic measures of productivity (h-index or citations) and the number of trips or the mileage covered.

The previous literature has drawn attention to the sizable carbon impact of academic conferences. The 
question is: are these sizable social costs worth it ${ }^{3}$ Do the benefits from these conferences outweigh their costs? And most importantly: how could we reduce the negative effects whilst preserving at least some of the beneficial effects?

One of the many benefits of conferences is the increased visibility of research, which in turn drives two distinct mechanisms, maturation and advertisement (de Leon and McQuillin, 2020). ${ }^{4}$ Through maturation the research paper improves. For example by networking one can establish new collaborations, which can lead to better papers; similarly, feedback at conferences can enhance the quality of research. Advertisement on the other hand means that the research can be introduced to other academics. It is possible that without exposure at conferences, many academics would not hear from a given piece of research.

One way to measure the magnitude of these beneficial mechanisms, is to look at citation numbers (de Leon and McQuillin, 2020, Wynes et al., 2019), which is what we chose to do in order to try to gauge how conference travelling contributes to citation numbers. More precisely, we wanted to test the following simple hypothesis. Starting from the premise that conferences contribute to the visibility of research, our hypothesis is that we may not need long trips to get to them, if presenting research locally might be just as beneficial in terms of citation numbers. This is an argument similar to Stroud and Feeley (2015), and Orsi (2012).

Hypothesis 1: It is the number of presentations at conferences, but not the distance travelled that matters for citation numbers.

The paper first introduces the data and discusses the travelling behaviour of conference speakers, the corresponding carbon impact of these trips, and the details of our citation data. Next, the hypothesis that long distance trips are not associated with more citations is tested. We then conclude with a discussion and a set of policy recommendations.

\footnotetext{
${ }^{3}$ Here we refer to social cost in a Coasian sense, which includes the direct private costs of attending these conferences, and the externalities they impose through increased carbon emission.

${ }^{4}$ As de Leon and McQuillin (2020) explain, maturation and advertisement can be thought of as the formation and diffusion of scientific knowledge, which has a rich literature but is tangential to the purposes of this paper.
} 


\section{Data and methods}

We assemble and (and publish) a novel dataset on a sample of economics conferences and the trips made by participating academics. ${ }^{5}$ The data was collected from the conference maker function of editorialexpress.com, which is a frequently used, although by no means exclusive platform for booking conferences in economics. The website contains details of historical conferences, going back to 2001. We did not have any specific selection mechanism, simply we wanted to include all conferences, where speaker-level information was available. Not all conferences archived on editorialexpress.com made all speaker-related information publicly available (and the data becomes patchier for older years). We found 263 conferences, where such data was available. For each of these events between 2001 and 2019, we recorded the list of speakers, the name of their home institution, and the title of their presentations. 99 (37\%) of these conferences were in North America, 107 (41\%) in Europe, 34 (13\%) in Asia-Pacific, 14 (5.5\%) in Latin America, and $9(3.5 \%)$ in other (Middle-East and Africa) countries. ${ }^{6}$ This included 55,006 presentations by 26,312 distinct speakers. The sample is not uniformly distributed over the analysed 18 years. In fact, for reasons unknown to us, in some years (e.g. 2011/12) speaker-level information was only made publicly available for a small number of conferences.

The longitude and latitude coordinates of the speaker's home institution and the conference venue were acquired using Google's geocoding API, and used to calculate the distance travelled to get to a conference. This distance was then multiplied by two to account for return trips. Of course not everyone travels to conferences from their home institution - or return there afterwards - but in the absence of more detailed data, we had to employ this as a working assumption.

\subsection{Travelling data}

Altogether, people travelled approximately 414 million kilometres (around 259 million miles) to present their research papers at these 263 conferences. This figure seems to be in a similar ballpark as others suggest. For example Green (2008) calibrates that the distance travelled by the 45,000 participants at the American Cardiac Society meeting added up to around 300 million miles.

\footnotetext{
${ }^{5}$ The choice of economics came from the affiliation of one of the authors, which meant that we were qualitatively familiar with the conferences in our sample.

${ }^{6}$ To see how this compares to the population of economics conferences, we looked at econbiz. de, which lists 1888 general economics conferences, of which $547(29 \%)$ were in the US+Canada, $880(47 \%)$ in the EU, and $461(24 \%)$ in other countries. Although this implies somewhat more EU and fewer US conferences, the distribution does not look strikingly different from our sample.
} 
Table 1 shows the split by the region of the conference and the speaker's home institution. The table reveals a number of interesting patterns. Most travel mileage by speakers from North America are associated with flying to Europe, and vice versa, most travel mileage by European speakers are linked to North American conferences. However, North American speakers travelled significantly more to European venues (a total of 90 million kms) than the other way around (European participation in North American conferences amassed around 51 million $\mathrm{kms}$ ). The total mileage of North American speakers was also the highest into other regions. Presenters from Asia-Pacific covered around the same mileage to Europe as to North America, and academics from Latin American countries travelled slightly more to Europe than to North America.

Table 1: Total distance (millions of $\mathrm{km}$ ) travelled to present a paper

\begin{tabular}{lccccc|c}
\hline & $\begin{array}{l}\text { North American } \\
\text { speaker }\end{array}$ & $\begin{array}{l}\text { European } \\
\text { speaker }\end{array}$ & $\begin{array}{l}\text { Asia-Pacific } \\
\text { speaker }\end{array}$ & $\begin{array}{l}\text { Latin American } \\
\text { speaker }\end{array}$ & $\begin{array}{l}\text { Other } \\
\text { speaker }\end{array}$ & Total \\
\hline North American venue & 37.22 & 50.97 & 22.65 & 3.43 & 19.69 & 133.96 \\
European venue & 89.93 & 21.66 & 22.46 & 4.48 & 27.9 & 166.43 \\
Asia-Pacific venue & 37.25 & 20.51 & 10.71 & 1.08 & 10.55 & 80.11 \\
Latina American venue & 5.63 & 2.78 & 1.06 & 1.32 & 3.75 & 14.54 \\
Other venue & 11.27 & 3.34 & 1.13 & 0.58 & 2.24 & 18.56 \\
\hline Total & 181.3 & 99.27 & 58.01 & 10.9 & 64.12 & 413.59 \\
\hline
\end{tabular}

263 conferences, 5,008 presentations, 26,312 speakers

Figure 2 offers more detail on the difference between speakers from different regions. The figure plots the Kernel density estimates of the distance travelled (per return trip) by frequent (more than 3 trips) and less frequent ( 3 trips or fewer) travellers. ${ }^{7}$ Among academics based in Europe, those who travel less frequently almost invariably travel short distances (large spike in the lighter density curve around a low average distance). The distribution of average travel distance is the most similar for frequent and less frequent travellers who are based at European institutions. For North American speakers, infrequent travellers are more likely to engage in long trips than their European counterparts (the kernel distribution is more spread out). It also appears that in North America, frequent travellers are much more likely to engage in long trips (the mode of the darker density curve for North America is around a 8-9000km roundtrip). Unsurprisingly, speakers from Asia-Pacific and Latin-American countries tend to travel more on average. What is more interesting, is that the difference between frequent and non-frequent travellers seems even more pronounced, with frequent travellers, on average taking much longer trips to conferences.

\footnotetext{
${ }^{7}$ Kernel density estimates are an alternative to histograms to visualise the empirical distribution of the data. It is an estimate of the underlying distribution (which is why there are sub-zero distances), and is calculated by weighting the distances between the data points: with more observations close to each other, the estimate will be higher, indicating a higher probability of observing that value.
} 
Figure 1: Distributions of distance travelled per return trip by frequent and less frequent travellers (kernel density estimates)
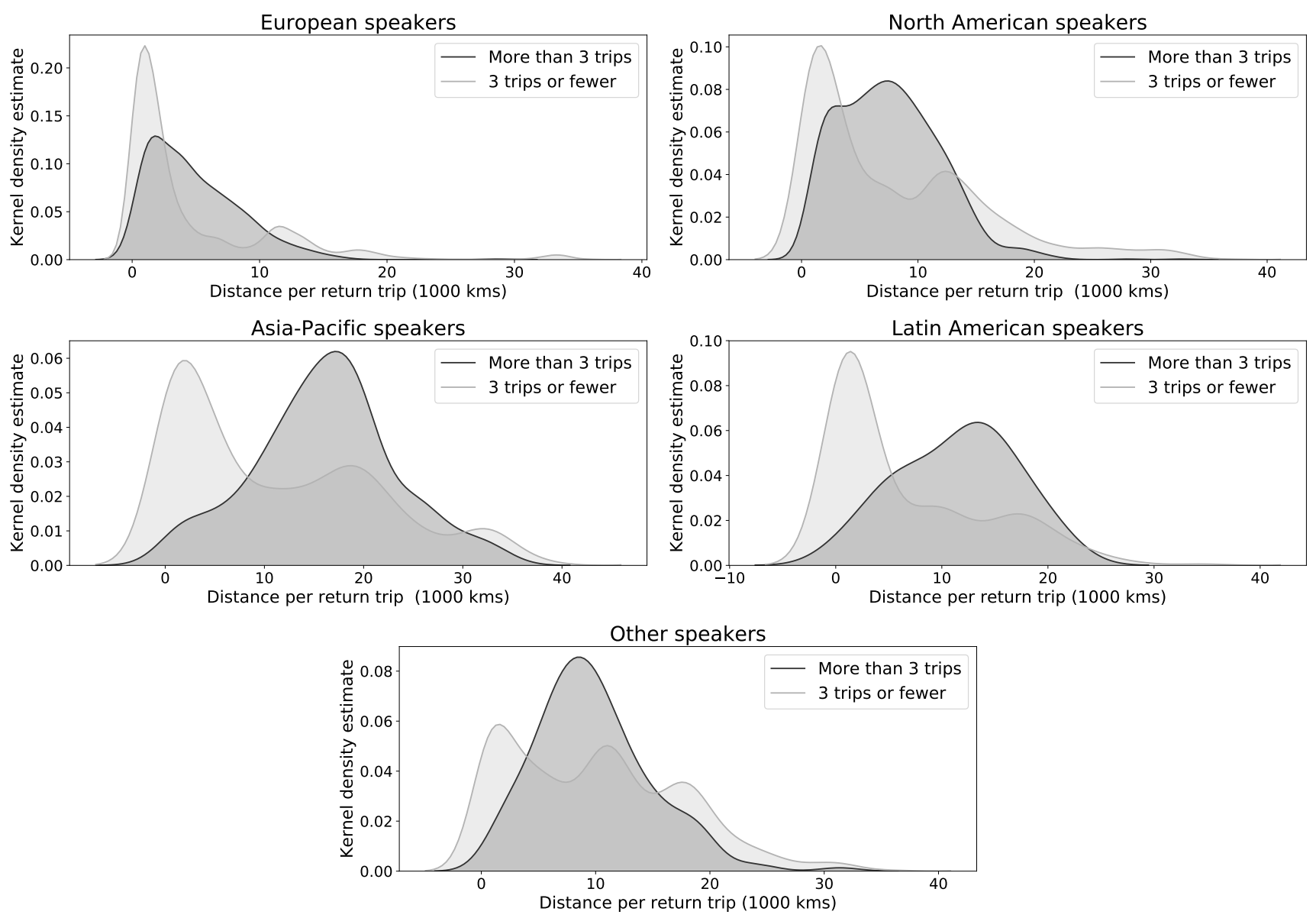

Tables 12 and 13 in the Appendix offer an insight into the distribution of the countries of venues and speakers. Table 12 shows that participants at conferences in countries in Western Europe travel a lower average distance than participants at conferences in North American and other countries. A similar pattern can be seen in Table 13, which shows the average travel distances by countries of the speakers' institutions. Participants from Europe travel, on average, less than their counterparts from other countries. The intuitive explanation to these findings is simply that there is a higher concentration of conference venues in Europe, and that European speakers (from nearby institutions) are more likely to attend these. These numbers are in line with the country-specific findings of Spinellis and Louridas (2013), with some differences: for example in Spinellis and Louridas (2013) North American speakers are among the greenest (lowest $\mathrm{CO}_{2}$ ), whereas in our sample they do fly longer distances to conferences.

When looking at the composition of participants, Table 2 shows that around 60 per cent of the speakers 
at North American or European events are from the same region. This number is between 40 and 50 per cent for the Asia-Pacific and for Latin America. North American speakers are the second most likely participants at Asia-Pacific or Latin American venues.

Table 2: Percentage of speakers at conferences by speaker and venue location (rows sum to 1)

\begin{tabular}{llllll}
\hline & $\begin{array}{l}\text { North American } \\
\text { speaker }\end{array}$ & $\begin{array}{l}\text { European } \\
\text { Speaker }\end{array}$ & $\begin{array}{l}\text { Asia-Pacific } \\
\text { speaker }\end{array}$ & $\begin{array}{l}\text { Latin American } \\
\text { speaker }\end{array}$ & $\begin{array}{l}\text { Other } \\
\text { speaker }\end{array}$ \\
\hline North American venue & 0.638 & 0.187 & 0.041 & 0.01 & 0.124 \\
European venue & 0.26 & 0.592 & 0.039 & 0.009 & 0.1 \\
Asia-Pacific venue & 0.276 & 0.17 & 0.432 & 0.006 & 0.116 \\
Latin American venue & 0.248 & 0.091 & 0.023 & 0.474 & 0.164 \\
Other venue & 0.505 & 0.236 & 0.03 & 0.031 & 0.199 \\
\hline
\end{tabular}

263 conferences, 5,008 presentations, 26,312 speakers

Table 3 shows the regional breakdown by the speakers' region. It reveals that academics were most likely to present in their own regions, with the exception of academics from Other regions, whose the most likely destination was North America and Europe. For North American academics, the second most popular presentation venue was in Europe, and vice versa for European academics. The second and third most frequent choices for Asia-Pacific and Latin American speakers were Europe and North America.

Table 3: Percentage of regions speakers presented at - by speaker's home region (rows sum to 1)

\begin{tabular}{lccccc}
\hline & $\begin{array}{c}\text { North American } \\
\text { venue }\end{array}$ & $\begin{array}{c}\text { European } \\
\text { venue }\end{array}$ & $\begin{array}{c}\text { Asia-Pacific } \\
\text { venue }\end{array}$ & $\begin{array}{c}\text { Latin American } \\
\text { venue }\end{array}$ & $\begin{array}{c}\text { Other } \\
\text { venue }\end{array}$ \\
\hline North American speaker & 0.599 & 0.28 & 0.065 & 0.016 & 0.04 \\
European speaker & 0.199 & 0.727 & 0.046 & 0.007 & 0.021 \\
Asia-Pacific speaker & 0.208 & 0.223 & 0.548 & 0.008 & 0.013 \\
Latin American speaker & 0.178 & 0.189 & 0.028 & 0.56 & 0.045 \\
Other speaker & 0.419 & 0.388 & 0.099 & 0.038 & 0.057 \\
\hline
\end{tabular}

263 conferences, 5,008 presentations, 26,312 speakers

Finally, as Figure 2 shows, time also seems to play a role, but its effect is more pronounced in some regions than in others. The number of trips in the sample shows a large jump from 2012 onward - due to the availability of conference data in the sample. Equally, the dip in 2011/12 is due to conference data missing on editorialexpress.com. What is interesting is that the average length of a return trip gradually decreases for European speakers, mildly increases for US speakers, and shows a more steady level for speakers from other regions. Whereas in the previous decade European speakers seemed to have covered more average mileage than their North American counterparts, this comparison flipped in the current decade. At the same time the proportion of European speakers at North American conferences remained 
stable, which suggests that the drop in the average miles travelled by European speakers is likely to be due to their increasing relative preference to present at European conferences.

Figure 2: Trips and travel distance by region, by year
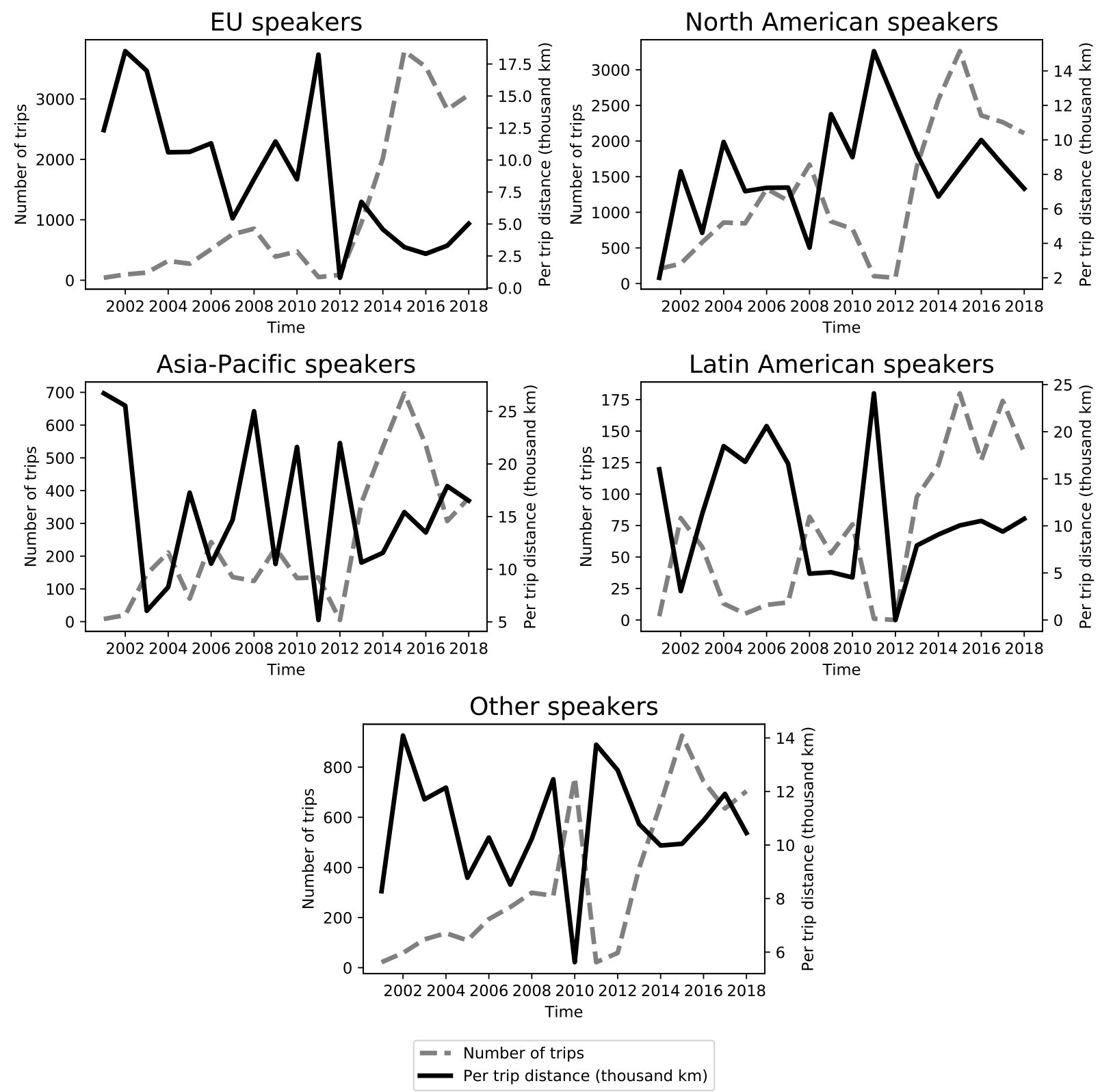

\subsubsection{What is the carbon impact of these trips?}

The carbon impact of flying by academics has been addressed by a number of previous works. Only a few of these, such as Ciers et al. (2019), had access to sufficiently detailed information on the individual journeys in order to calculate precise emission figures. For example, take-off and landing are the most 
fuel intensive (and therefore emission intensive) portions of the flight. For this reason, knowing the exact itinerary of the researchers would be required to calibrate the relative weight of take-off and landing (many shorter trips would have a per/mile larger impact than a single longer trip of the same distance as the sum of the shorter trips). The per-passenger (grams/passenger $\mathrm{km}$ ) emission also depends on whether one flies business or economy (per passenger emission is higher when one travels on business because of the space allocated to these passengers). ${ }^{8}$ Finally, per-passenger emission also depends on how full the plane is, which information is unlikely to be available to researchers.

Instead, most previous papers rely on simple rules of thumb, and provide approximate emission figures. For example, Callister and Griffiths (2007) look at trips to the American Thoracic Society (ATS) International Conference (San Diego, 2006), and assume travel on a Boeing 737 for journeys of 2,000 km or less, and a Boeing 747 for journeys greater than 2,000 km.

Table 4: Academic flying carbon emission estimates in previous studies

\begin{tabular}{|c|c|c|c|c|c|}
\hline Paper & Sample & Number of trips & $\begin{array}{l}\text { Total distance } \\
\text { (million } \mathrm{km} \text { ) }\end{array}$ & $\begin{array}{l}\text { Total emission } \\
\text { (tonnes) }\end{array}$ & $\begin{array}{l}\text { Per trip emission } \\
(\mathrm{kg})\end{array}$ \\
\hline Hischier and Hilty (2002) & $\begin{array}{l}\text { 15th International Environmental } \\
\text { Informatics Symposium }\end{array}$ & 109 & 0.24 & 71 & 642 \\
\hline Callister and Griffiths (2007) & $\begin{array}{l}\text { The American Thoracic Society (ATS) } \\
\text { International Conference in San Diego } 2006\end{array}$ & 14914 & 100 & 10800 & 724 \\
\hline Orsi (2012) & $\begin{array}{l}2007 \text { World Congress of the International } \\
\text { Association of Landscape Ecology }\end{array}$ & 734 & & 461 & 628 \\
\hline Spinellis and Louridas (2013) & Various disciplines & 32264 & & 25843 & 801 \\
\hline Stroud (2015) & $\begin{array}{l}\text { Four conferences of the International } \\
\text { Biogeography Society }\end{array}$ & 1759 & 17 & $4400-5280$ & $2500-3000$ \\
\hline Cies et al (2018) & $\begin{array}{l}\text { Researchers from the École Polytechnique } \\
\text { Fédérale de Lausanne (EPFL) (2014 to 2016) }\end{array}$ & 14949 & 100 & 14603 & 977 \\
\hline Wynes et al. (2019) & $\begin{array}{l}705 \text { travellers at the University of } \\
\text { British Columbia }\end{array}$ & 1769 & & 3019 & 1707 \\
\hline \multirow[t]{4}{*}{ Arsenault (2019) } & $\begin{array}{l}\text { Annual travelling data for Université de } \\
\text { Montréal staff: }\end{array}$ & & & & \\
\hline & Professors & & & & 1515 \\
\hline & Post docs & & & & 978 \\
\hline & Graduate students & & & & 606 \\
\hline
\end{tabular}

Table 4 compares a number of these previous works in terms of the estimated per trip carbon emissions. The table is incomplete, as not all papers report all figures included in the table. For most papers, per trip emission remains between $600-1000 \mathrm{~kg}$, but there are a few outliers. For example, the figures in Stroud and Feeley (2015) are strikingly high, but these numbers are based on guidelines set by the USA's Environmental Protection Agency in 2008, which are higher than the assumptions used in the other papers. Moreover, the trips in Stroud and Feeley (2015) were more likely long distance than in the other papers. Finally, US airlines tend to be associated with higher emission on average, and emission efficiency has

\footnotetext{
${ }^{8}$ The difference can be four-fold, see for example here: https://www. clevel.co.uk/flight-carbon-calculator/.
} 
much improved since 2008.

Similarly to these papers, we made some simplifying assumptions when calibrating our $\mathrm{CO} 2$ emission figures. ${ }^{9}$ Our carbon emission assumptions are based on a study by the Transition Pathway Initiative (TPI), which reports carbon emission levels for 19 airlines. ${ }^{10}$ These figures already average out over all factors that we do not observe for our study (such as flying business or economy, or radiative forcing, etc), but which can impact $\mathrm{CO}_{2}$ emission. Our measure of $\mathrm{CO}_{2}$ emission was therefore a simple product of the distance travelled, and the $\mathrm{CO}_{2} / \mathrm{km} /$ passenger figures derived from airline averages. These emission figures were adjusted for how fuel efficiency changed over the period of the study. For this we assumed a 1.5 percent annual increase in fuel efficiency, which is a common target by airlines, and adjusted the emission figures for each year as: $e_{i}=\frac{e_{2020}}{0.985^{2020-i}}$, where $e_{i}$ denotes emission for year $i$. Finally, for the emission calculations we took out all trips that were shorter than 300 miles (just under 500km) one way, because people are likely to use alternative means of transport for shorter journeys. For these trips we assumed zero emission, which implies that the calibrated emission figures are likely to be conservative. These short trips were only omitted for calculating carbon emissions and not for the remaining parts of our paper.

In comparison with the estimates in Table 4 where the lower bound per-trip emission figure was around $600 \mathrm{~kg}$, to get a figure in the same ballpark, we would have to assume that the flights taken by the academics in our sample operated at around $75 \mathrm{~g}$ per passenger $\mathrm{km}$ emission. Using the TPI data, this corresponds to the greenest airlines. For a per-trip 900kg emission level, which was approximately the middle point of previous per-trip emissions, our participants would have had to be flying with airlines operating at around $125 \mathrm{~g}$ per passenger km emission, which is the average carbon performance of the airlines listed by TPI.

Table 5 shows the emission figures for our sample of trips, broken down by the geographical region of the conference venue, using an average emission scenario (125g per passenger km emission). ${ }^{11}$ When looking at the per-conference and per-presentation figures, it appears that North American venues contribute the lowest amount of per trip $\mathrm{CO}_{2}$ emission - presumably because a larger proportion of the speakers at these conferences are from North American institutions - closely followed by Europe. Conferences in other regions, especially in Asia-Pacific have higher $\mathrm{CO}_{2}$ emission figures, as these are often held at venues that are distant to most participants. Similarly, as speakers from Asia-Pacific countries often have to travel to

\footnotetext{
${ }^{9}$ Although we focus on carbon dioxide $\left(\mathrm{CO}_{2}\right)$ emission, we acknowledge that flying has other harmful effects (for example nitrogen oxide and nitrogen dioxide emission). As such we only provide conservative estimates of the true scale of harmful effects.

10 http://www. lse.ac.uk/GranthamInstitute/tpi/wpcontent/uploads/2019/03/Management-quality-and-carbonperformance-ofairlines-040319-1730.pdf

${ }^{11}$ Tables 14 and 15 in the Appendix provide more details, and offer calibrations under more extreme assumptions.
} 
distant conferences, their per-trip emission numbers are significantly higher.

Table 5: Flying-related $\mathrm{CO}_{2}$ emission figures (metric tonnes) - broken down by venue/speaker

\begin{tabular}{lllllll}
\hline & All & $\begin{array}{l}\text { North } \\
\text { America }\end{array}$ & Europe & Asia-Pacific & $\begin{array}{l}\text { Latin } \\
\text { America }\end{array}$ & Other \\
\hline \multicolumn{2}{l}{ By venue's region } & & & & & \\
\hline Per conference & 187.86 & 163.92 & 180.15 & 288.11 & 129.16 & 255.36 \\
& $(196.53)$ & $(165.15)$ & $(209.11)$ & $(218.84)$ & $(131.81)$ & $(252.7)$ \\
Per trip & 0.9 & 0.75 & 0.78 & 1.81 & 1.24 & 1.26 \\
& $(0.98)$ & $(0.83)$ & $(0.86)$ & $(1.4)$ & $(1.1)$ & $(0.93)$ \\
\hline By speaker's region & & & & & \\
\hline Per trip & 0.9 & 0.95 & 0.58 & 1.63 & 1.05 & 1.21 \\
& $(0.98)$ & $(0.92)$ & $(0.81)$ & $(1.38)$ & $(1.05)$ & $(0.93)$ \\
\hline
\end{tabular}

263 conferences, 5,008 presentations, 26,312 speakers

Standard deviation in parentheses.

\subsection{Data for the citation analysis}

As a next step we looked at citation data for the papers that were presented at the sampled conferences. We used Microsoft Academic for this purpose. ${ }^{12}$ Around $60 \%$ of the presentations were matched to a paper with citation figures, leaving us with a reduced sample of 31,725 presentations (trips) by 16,626 distinct speakers in the 18 year sample period. ${ }^{13}$ This observed sample of 31,725 presentations also included 9,779 trips presenting papers where Microsoft Academic recorded zero citations at the time of collecting our data. It is possible that Microsoft misses some citations, therefore the proportion of papers with no citations is potentially smaller than what we can record from the available data. We were not able to collect information on the papers that were not found via our Microsoft Academic search.

In conducting our search we looked for the title of the presentation and the name of the speaker together, to try to pick up minor changes in the final published title. We then grouped the data by each speaker. ${ }^{14}$ Once the data was aggregated at speaker-level, the following variables were added to our travel distance and travel frequency data (Table 11 in the Appendix presents the summary statistics):

\footnotetext{
${ }^{12}$ We opted against using Google Scholar as they do not provide a data API.

${ }^{13}$ When randomly comparing with citation numbers on Google Scholar, we found that there was sometimes a discrepancy, probably due to the difference in their search algorigthms, but the difference between the Google and Microsoft figures tended to be small.

${ }^{14}$ As speaker names often appear in different forms (e.g. with or without middle names), we used approximate string matching to find the same names. Approximate (or fuzzy) string matching refers to the technique of finding strings that match a pattern approximately - but not perfectly. For example the entries Peter Ormosi, Peter L Ormosi, and Peter Laszlo Ormosi do not perfectly match, although they refer to the same author. With various approximate matching algorithms, one can adjust how much distance between two strings should be tolerated for a match in order to include all permutations of the same name or title.
} 
Citations: The total number of citations that the presented paper received as of December 2019. This is normalised by the age of the paper (the citation count is divided by age in years), which is a common practice in works using citation count. ${ }^{15}$ This citation number includes citations to the most cited version of the paper, if multiple versions were found on our data source (e.g. working paper and final publication). We do not have further information on the composition of this citation data (i.e. who cite these papers, what percentage are self citations, etc).

Table 6 shows the average number of citations (age-weighted) for those papers that were presented at conferences included in our sample. The table reveals that most citations are associated with presenting at North American venues, and that European speakers presented research with more citation at nonEuropean venues. It is also interesting that venues in our 'other' region are associated with presenting high citation North American and European papers. The causality can go both ways, good conferences contributing to higher citations, or conferences (for example in the 'other' region) inviting papers and speakers with high citation numbers. The next variable plays an important role in distinguishing between these two effects.

Table 6: Age weighted average citation/paper by speaker and venue region

\begin{tabular}{lccccc}
\hline & $\begin{array}{c}\text { North American } \\
\text { speaker }\end{array}$ & $\begin{array}{c}\text { European } \\
\text { speaker }\end{array}$ & $\begin{array}{c}\text { Asia-Pacific } \\
\text { speaker }\end{array}$ & $\begin{array}{c}\text { Latin American } \\
\text { speaker }\end{array}$ & $\begin{array}{c}\text { Other } \\
\text { speaker }\end{array}$ \\
\hline North American venue & 4.413 & 2.448 & 1.223 & 1.574 & 2.317 \\
European venue & 3.736 & 1.646 & 0.980 & 0.830 & 1.326 \\
Asia-Pacific venue & 3.721 & 1.955 & 1.303 & 0.581 & 1.470 \\
Latina American venue & 1.704 & 1.894 & 3.513 & 0.937 & 1.956 \\
Other venue & 4.211 & 2.553 & 0.513 & 1.125 & 1.924 \\
\hline
\end{tabular}

Speaker total citations (academic fame): The number of citations the speaker had on Microsoft Academic in December 2019 (excluding the citations for the papers presented). This intends to approximate the academic standing of the presenter (higher numbers reflecting more experienced and better known academics). This is needed to deal with a potential source of endogeneity (i.e. people of higher academic stature can trigger more citations and at the same time could be invited to more conferences). ${ }^{16}$ Table 7 shows that highly cited academics from North American and European institutions are more likely to present at conferences that are further from their home institutions. This is likely to be a reputation effect (academics with higher reputation are more likely to be invited, or more likely to have access to funding

\footnotetext{
${ }^{15}$ In economics conference papers are not typically cited separately, the citation relates to the working paper and the final published versions of the paper.

${ }^{16}$ Wynes et al. (2019) for example finds strong correlation between age and academic standing and the number of trips and mileage.
} 
to pay for these longer trips). Interestingly, in the case of European speakers, those who travel to North American conferences seem to have lower total citations, which could suggest that more early career academics travel from Europe to North America to present their work (we call this the exposure effect). Venues in our 'Other' region are most likely to invite highly cited North American academics, but seem less selective when it comes to inviting speakers from other regions. Asia-Pacific venues are also more likely to invite high citation North American and European academics.

Table 7: Total speaker citations (age-weighted) by speaker and venue regions

\begin{tabular}{lccccc}
\hline & $\begin{array}{c}\text { North American } \\
\text { speaker }\end{array}$ & $\begin{array}{c}\text { European } \\
\text { speaker }\end{array}$ & $\begin{array}{c}\text { Asia-Pacific } \\
\text { speaker }\end{array}$ & $\begin{array}{c}\text { Latin American } \\
\text { speaker }\end{array}$ & $\begin{array}{c}\text { Other } \\
\text { speaker }\end{array}$ \\
\hline North American venue & 272.24 & 173.25 & 137.80 & 35.02 & 136.16 \\
European venue & 340.16 & 189.99 & 123.85 & 61.75 & 121.22 \\
Asia-Pacific venue & 333.38 & 284.33 & 146.37 & 41.34 & 98.27 \\
Latina American venue & 169.77 & 165.67 & 52.97 & 37.77 & 40.45 \\
Other venue & 366.21 & 154.72 & 97.87 & 29.76 & 83.08 \\
\hline
\end{tabular}

Conference size: The number of participants at the conference where the speaker gave their presentation - averaged over all presentations if a speaker had more than one presentations.

\section{Model used for citation analysis}

Let us assume - given our data - that the number of citations to a paper presented at a conference is defined by the following linear relationship:

$$
\text { citations }_{i}=\beta_{0}+\beta_{1} \text { dist }_{i}+\beta_{2} \text { trips }_{i}+\beta_{3} \text { fame }_{i}+\vec{\gamma} \vec{X}+\varepsilon_{i}
$$

Where dist $_{i}$ stands for the per-presentation distance travelled by speaker $i$. trips $_{i}$ denotes the number of trips by the same speaker $i$. fame $e_{i}$ is our measure of academic fame of speaker $i$ (total citations minus citations to the presented papers) as explained above. $\vec{X}$ is an $(i \times k)$ matrix of $k$ observed covariates for each speaker $i$, with the corresponding $(1 \times k)$ coefficient vector $\vec{\gamma}$. Finally, $\beta_{0}$ is the intercept, and $\epsilon_{i}$ is the idiosyncratic error term. Hypothesis 1 implies that $\beta_{1}=0$ and $\beta_{2}>0$.

The observed covariate matrix $\vec{X}$ contains the following variables. The number of participants at the conferences where the speaker presented. Four dummy variables for four groups of speakers, based on their home institution (US+Canada, Asia-Pacific, Latin America, Other). This means that presentations 
by speakers from the fifth group (European countries) are used as benchmark (or base) group in the estimates, against which the coefficients can be compared. $\vec{X}$ also includes a set of four variables, where the speaker region dummy variables are each interacted with the distance covered (dist), and the number of trips (trips). All of the above variables are then interacted with academic stature (fame). Finally, we also control for the year of the presentation, and the number of attendants at the conference where the presentation was held.

\section{Results}

Table 8 below shows the headline results of estimating the parameters in Equation (1). ${ }^{17}$ The table has 4 columns. Model 1 controls for all observed features as listed above. Model 2 excludes the fame variable, Model 3 excludes the interaction terms, and Model 4 only uses the three main variables of interest (distance, trips, and fame). To allow comparison across different units, the variables have been standardised (mean zero and unit variance), therefore coefficients can be interpreted as the effect of 1 standard deviation change in the independent variable. For example, using the results in Model 1, one standard deviation change in the number of trips results in a 0.1391 standard deviation change in citation numbers. Because we control for all regions except Europe, the results in Table 8 can be interpreted for European speakers only - later we discuss the regional differences.

All model specifications support part of Hypothesis 1, whereby the effect of the number of trips is positive and significant $\left(\beta_{2}>0\right)$. However, for European speakers, the effect of the average distance travelled is also significant in some models, although the coefficient is small (around a sixth of the effect of the frequency of trips). ${ }^{18}$ With fame included in the model, we control for the possibility that academics with wider reputation (and more citations) get invited to do more trips. The fame coefficient is positive and strongly significant, which confirms that papers by academics with increased fame are more likely to be cited. Interestingly, the attendance coefficient (conference size) is negative and significant, suggesting that larger conferences might contribute less to citations. The intuition to this would be that the chances of an individual presentation to attract interest are smaller when there are many other papers presented at the same conference. This latter finding would suggest that in the dichotomy of de Leon and McQuillin (2020), the advertising function of conferences dominates the maturation mechanism.

\footnotetext{
${ }^{17}$ Full regression results are given in Table 16 in the Appendix.

${ }^{18}$ The paper puts less emphasis on interpreting the exact magnitude of the coefficients. The low $R^{2}$ figures imply that the estimated model is not a very good one for prediction, but our interest is not in prediction, rather in the relationship between 3 variables to test Hypothesis 1 .
} 
Table 8: Main citation results

\begin{tabular}{lllll}
\hline & Model 1 & Model 2 & Model 3 & Model 4 \\
\hline distance & $0.0204^{*}$ & $0.0271^{* * *}$ & -0.0032 & 0.0029 \\
& $(0.0111)$ & $(0.0100)$ & $(0.0055)$ & $(0.0051)$ \\
trips & $0.1288^{* * *}$ & $0.1494^{* * *}$ & $0.2383^{* * *}$ & $0.2452^{* * *}$ \\
& $(0.0139)$ & $(0.0159)$ & $(0.0137)$ & $(0.0139)$ \\
fame & $0.0686^{*}$ & & $0.1922^{* * *}$ & $0.1982^{* * *}$ \\
& $(0.0393)$ & & $(0.0308)$ & $(0.0315)$ \\
distance x fame & $-0.0617 *$ & & & \\
trips x fame & $(0.0367)$ & & & \\
& 0.0363 & & & \\
conference size & $(0.0287)$ & & & \\
& $-0.0131^{* * *}$ & $-0.0113^{* *}$ & $-0.0157 * * *$ & \\
\hline $\mathbf{N}$ & $(0.0049)$ & $(0.0049)$ & $(0.0048)$ & \\
R2 & 16625 & 16625 & 16625 & 16625 \\
\hline & 0.15 & 0.11 & 0.13 & 0.12 \\
\hline
\end{tabular}

Standard errors in parentheses.

$* \mathrm{p}<.1, * * \mathrm{p}<.05, * * * \mathrm{p}<.01$

Table 9 summarises the regional effects (the coefficients are from the full regression results in Table 16 in the Appendix). It shows how academics from the listed regions differ from their European counterparts. For each region below, the coefficients can be interpreted as the effect of these factors in the first column in comparison to the effect of the same factors among European academics. For example, the coefficient 0.2001 for the trips variable for North American speakers suggests that the number of trips matters more for citation for North American speakers (for European speakers this coefficient was 0.13 standard deviations, for North American speakers, it is 0.2 standard deviations higher).

The first row (speaker dummy) shows how academics differ in terms of their citation count when compared to their European counterparts. North American academics have significantly higher, and Asia-Pacific speakers have lower citation numbers. The second row (distance) indicates the relationship between travelling distance and academic citations for each region. In Table 8 the corresponding coefficient is 0.02 . In comparison, the effect of distance is around 0.03 standard deviation lower for North America and AsiaPacific speakers, and not significantly different for Latin American and Other speakers. This suggests that the second part of our hypothesis (distance travelled does not matter for more citations) can be rejected for European academics (and potentially for Latin American and Middle-Eastern and African academics, although their sample size is too little to suggest confidence in the findings), but not for North American 
and Asia-Pacific academics.

The third row (trips) suggests that for North America, the number of trips contributes to even more citations. For academics from Asia-Pacific and Latin American institutions the number of trips is less important for citation numbers. Finally, for North American academics, fame is associated with significantly higher number of citations. Otherwise fame does not change the relationship between distance/trips and citations.

Table 9: Difference between speakers from different regions - benchmark is European speakers

\begin{tabular}{lllll}
\hline interaction variable & North American & Asia-Pacific & Latin American & Other \\
\hline speaker dummy & $0.2061 * * *$ & $-0.0744 * * *$ & 0.0763 & 0.0038 \\
& $(0.0207)$ & $(0.0191)$ & $(0.2144)$ & $(0.0238)$ \\
distance & $-0.0319 * *$ & $-0.0253 *$ & 0.0092 & 0.0027 \\
\multirow{2}{*}{ trips } & $(0.0159)$ & $(0.0132)$ & $(0.0708)$ & $(0.0217)$ \\
& $0.2001 * * *$ & $-0.0638 * * *$ & $-0.1394 *$ & 0.0531 \\
speaker x fame & $(0.0307)$ & $(0.0233)$ & $(0.0739)$ & $(0.0347)$ \\
& $0.1782^{* *}$ & 0.0071 & 0.9254 & 0.0592 \\
distance x fame & $(0.0794)$ & $(0.0498)$ & $(1.0694)$ & $(0.0835)$ \\
& 0.0716 & 0.0274 & 0.1702 & $0.2056 * *$ \\
trips x fame & $(0.0618)$ & $(0.0413)$ & $(0.3707)$ & $(0.0903)$ \\
& -0.0433 & -0.0218 & -0.3212 & -0.0105 \\
& $(0.0427)$ & $(0.0381)$ & $(0.3973)$ & $(0.1004)$ \\
\hline
\end{tabular}

Standard errors in parentheses.

$* \mathrm{p}<.1, * * \mathrm{p}<.05, * * * \mathrm{p}<.01$

One disadvantage of such aggregate results is that it provides average findings over the individuals and masks the differences between each case. Even when controlling for the specific regions, given the large number of interaction terms, it becomes difficult to interpret the results. To take a more detailed look, we narrow our focus to North American and European venues and speakers, which is around $80 \%$ of our sample. To do this, we re-run our regressions but only on the European and North American part of our data. In this exercise we kept European speakers as our baseline category. The results in Table 10 reveal some additional details. Firstly, the coefficient of the distance variable is now significant for all bar one of the model specifications. It suggests that citation to papers by European academics benefits from flying to present at conferences further away from Europe. Because now we only have Europe and North America in our sample we know that these longer trips equate to cross-Atlantic flights. On the other hand, this effect is cancelled out the other way around: North American speakers do not benefit the same way from cross-Atlantic presentations (see distance x speaker (North America). Otherwise Table 10 confirms all our previous findings (more trips, more reputation, and being from a North American institutions are all associated with more citations). 
Table 10: Citation results for North American/European sample only

\begin{tabular}{|c|c|c|c|c|}
\hline & model 1 & model 2 & model 3 & model 4 \\
\hline distance & $\begin{array}{l}0.0269 * * \\
(0.0110)\end{array}$ & $\begin{array}{l}0.0286^{* * * *} \\
(0.0098)\end{array}$ & $\begin{array}{l}0.0096 \\
(0.0076)\end{array}$ & $\begin{array}{l}0.0301 * * * \\
(0.0077)\end{array}$ \\
\hline trips & $\begin{array}{l}0.1056^{* * * *} \\
(0.0129)\end{array}$ & $\begin{array}{l}0.1209 * * * \\
(0.0143)\end{array}$ & $\begin{array}{l}0.2150^{* * * *} \\
(0.0143)\end{array}$ & $\begin{array}{l}0.2188^{* * * *} \\
(0.0145)\end{array}$ \\
\hline fame & $\begin{array}{l}0.0930 * * * \\
(0.0358)\end{array}$ & & $\begin{array}{l}0.1917 * * * * \\
(0.0350)\end{array}$ & $\begin{array}{l}0.1950^{* * * *} \\
(0.0355)\end{array}$ \\
\hline speaker (North America) & $\begin{array}{l}0.1918 * * * \\
(0.0199)\end{array}$ & $\begin{array}{l}0.2023 * * * \\
(0.0178)\end{array}$ & $\begin{array}{l}0.1745^{* * * *} \\
(0.0163)\end{array}$ & \\
\hline distance x speaker (North America) & $\begin{array}{l}-0.0284^{*} \\
(0.0158)\end{array}$ & $\begin{array}{l}-0.0268^{*} \\
(0.0149)\end{array}$ & & \\
\hline distance $\mathrm{x}$ fame & $\begin{array}{l}-0.0132 \\
(0.0320)\end{array}$ & & & \\
\hline distance x speaker (North America) x fame & $\begin{array}{l}0.0152 \\
(0.0573)\end{array}$ & & & \\
\hline trips x speaker (North America) & $\begin{array}{l}0.1794 * * * \\
(0.0277)\end{array}$ & $\begin{array}{l}0.2160 * * * \\
(0.0291)\end{array}$ & & \\
\hline trips $x$ fame & $\begin{array}{l}0.0205 \\
(0.0232)\end{array}$ & & & \\
\hline trips x speaker (North America) fame & $\begin{array}{l}-0.0311 \\
(0.0411)\end{array}$ & & & \\
\hline speaker (North America) x fame & $\begin{array}{l}0.1482^{*} \\
(0.0776)\end{array}$ & & & \\
\hline conference size & $\begin{array}{l}-0.0150 * * * \\
(0.0053)\end{array}$ & $\begin{array}{l}-0.0125 * * \\
(0.0052)\end{array}$ & $\begin{array}{l}-0.0172 * * * \\
(0.0054)\end{array}$ & \\
\hline Intercept & $\begin{array}{l}-0.1010 * * * \\
(0.0100)\end{array}$ & $\begin{array}{l}-0.1040 * * * \\
(0.0083)\end{array}$ & $\begin{array}{l}-0.0863 * * * \\
(0.0082)\end{array}$ & $\begin{array}{l}0.0000 \\
(0.0085)\end{array}$ \\
\hline $\mathbf{N}$ & 12396 & 12396 & 12396 & 12396 \\
\hline R2 & 0.12 & 0.09 & 0.11 & 0.11 \\
\hline
\end{tabular}

Standard errors in parentheses.

$* \mathrm{p}<.1, * * \mathrm{p}<.05, * * * \mathrm{p}<.01$

As a verification, and further robustness check, we also run a ridge regression using the model reported under Model $1 .{ }^{19}$ Ridge regressions are often utilised with data that is likely to suffer from multicollinearity, which was a possibility in our case, where the number of trips and fame are included as independent variables in the same model. The ridge regression adds a regularisation term to the conventional OLS minimalisation of the sum of squared residual. This term penalises large coefficients. As the regularisation parameter tends to zero, the ridge coefficients converge to the OLS coefficients. The idea is: if multicollinearity caused biased OLS estimates, then the ridge estimates (with non-zero regularisation parameter) will be different from the OLS estimates. Table 18 in the Appendix shows these coefficients.

${ }^{19}$ Ridge regressions assume that the predictors in the estimated model are standardised. 
There appears to be some bias in the distance coefficient, but the bias is away from zero - which corroborates our story.

Finally, given the large number of interaction terms, and our need to gain some information on the relative importance of our main features in driving citation numbers, we also constructed a regression tree. Because traditional econometric methods offer limited use to classify data by their importance, classification and regression tree (CART) methods are often summoned in cases where the underlying research question is on the relative importance of the different predictors in driving an outcome variable - similar to the question we have at hand. ${ }^{20}$ Using a regression tree, as shown in Figure 3 in the Appendix, is a parsimonious way to demonstrate the relationship between the number of trips and the distance travelled, and our dependent variable, the number of citations. Our regression tree suggests that the most important factors in determining citation count are academic fame, the number of trips, and whether a speaker is from North America or not. The per-trip distance travelled plays no (or vary little) role once we control for the number of trips.

\section{Discussion}

\subsection{What do our results indicate?}

First, we presented detailed information on the distance travelled by speakers attending a sample of 263 economics conferences. How much we can generalise from the findings below hinges on how much the reader believes our assumption, that our observed sample is a random representation of the total sample. From our data we can deduct a number of simple stylised facts. For example, European academics tend to travel shorter distances to present their work, and for EU speakers we can observe a clear decline, over time, in the distance travelled to conferences. In our regional breakdown, North American speakers travelled more, and academics from regions other than Europe or North America travelled most. Of course this is largely the result of the geographical distribution of conferences. Conferences are much more concentrated in Europe than in North America, and an academic outside of Europe and North America most likely ends up having to do cross-continental trips to disseminate their work to European or North American audiences.

${ }^{20}$ CART analysis is a tree-building technique, which is suitable when the outcome (dependent) variable is continuous. 
We also offer some total figures of all trips covered in our sample $(55,006$ trips and around 414 million kms travelled). To put these numbers in perspective, the American Economic Association provides an extensive list of all economics conferences on its radar. ${ }^{21}$ This list contains 25,247 economics conferences for a somewhat shorter period than ours (2003-2019), which would imply that the sample we use in this paper is (at most) around 1 percent of all economics conferences. Both intuition and our data suggests that the conference size (number of presentations at a given conference) variable fits the lognormal distribution reasonably well. ${ }^{22}$ Using this as an assumption, one can attempt to extrapolate from our sample that if our sample of 263 conferences included 55,006 trips, the 25,247 economics conferences - following the same lognormal distribution - would have included 6.6 million trips, and a total of around 50 billion kms flown, which is around 5.5 million metric tonnes of $\mathrm{CO}_{2}$ under our average carbon emission assumptions - equivalent to around a tenth of the total annual carbon emission of Hungary or Sweden. ${ }^{23}$ Of course, the conference-maker website, which we used to collect our data, may be more likely to include larger conferences. This would imply that our 1 percent sample is not randomly taken and therefore the above total figures would be an upper bound of the real figures. Still, this gives us a feel about the potential magnitude of flying-related carbon emissions of all economics conferences.

Linking this data to citation numbers, the paper offers evidence that travelling to more conferences is typically associated with higher citation numbers, but the relationship between the distance travelled and the number of citations varies across regions. Notably, European academics seem to benefit (in terms of citation numbers) from cross-Atlantic trips but the same is not true for their North American counterparts.

One explanation is that highly cited North American academics are more likely to get an invitation (reputation effect). On the other hand, more early career economists do cross-Atlantic trips to develop and corroborate their reputation (exposure effect), as was seen in Table 7. This explanation is further supported by the fact that, in economics, North American venues are often considered to attract more distinguished audiences, possibly because many of the top economists are concentrated in best US/Canadian universities. As we have seen in Table 7 more prominent North American speakers present in Europe than the other way around (the total citation count of North American speakers presenting in Europe is twice the total citation count of European speakers presenting in North America).

For North American speakers, travelling to many conferences is associated with much increased citation

\footnotetext{
${ }^{21}$ https://www. aeaweb.org/rfe/conferences.php

${ }^{22}$ The lognormal distribution - whereby the log of a random variable is normally distributed - is frequently used to fit to size data.

${ }^{23}$ For these back of the envelop figures we first calibrated the parameters of the distribution of conference size in the sample (assuming lognormal distribution), then using these parameters, we generated a random sample of 25,247 lognormally distributed conferences sizes, which gave us the total number of trips. Multiplying this by the average distance in our sample we got the total distance travelled.
} 
numbers, but it makes no difference (in terms of citation numbers) whether these conferences are local or distant. Interestingly, for Asia-Pacific speakers only the number of trips has a small positive effect on citations, distance does not. This would suggest that for Asia-Pacific academics long-distance trips to European or North American venues on average do not contribute to more citations. For Latin American speakers there seems to be very little (if any) relationship between the number of trips and distance travelled and citations. Finally, for academics of other regions, the findings are similar to those of their European counterparts.

The finding of no relationship between the distance travelled (i.e. the carbon impact) and citation (except for European academics) is in line with previous works, such as Wynes et al. (2019), who found that for academics at the University of British Columbia there was no relationship between air travel emissions (which is directly proportional to our distance measure) and metrics of academic productivity. In this respect, our work provides corroborating evidence to the findings of Wynes et al. (2019). However, as additional evidence, our results highlight the heterogeneity across academics at different institutions. We were able to explore some of this heterogeneity (the contrast between North American and European academics), but more focused, and less aggregate studies are needed to further explore the geographical and institutional differences.

\subsection{Potential limitations}

Our approach inevitably produces a number of questions. First of all, what does our outcome variable, citation, measure? Citations, and other academic productivity and quality metrics have been extensively researched, and a comprehensive review is beyond the scope of this paper. Recent works have emphasised that citation metrics have a number of components. Our primary interest is in short-term citations, which is often referred to as a sign of engagement in current debate, in contrast to long-term citations, which is a sign of maturity and indicator of the solidification of research in knowledge (Leydesdorff et al., 2016). Empirically, we are unable to separate out the individual layers of citations. Moreover, we also cannot separate out self-citations. However, whilst we acknowledge that citation measures can incorporate various effects, we also believe that at least one of these effects reflect on how intensively a researcher engages with their research environment, for example through presenting at academic conferences.

We also acknowledge that citations are not the only way conferences can make a contribution. There are numerous other benefits, such as improved networking, new collaborations, and so on. Nevertheless, one 
would reasonably hope that all of the benefits that an academic expects a conference to deliver should manifest, at least to some extent, in the number of times the presented paper is cited. Put differently, we do not believe it is far-fetched to expect that an increase in any of the conference-benefits would be associated with increased citations. Among other reasons, such as the availability of data, this would explain the large number of papers that use citations (and related bibliometric measures) as a metric for the benefit of conferences and academic mobility. ${ }^{24}$

The second main potential issue is the availability of citation data. Given our sample size, we had no choice but to automate data collection. Through this process we found citation for around $60 \%$ of our sample on Microsoft Academic. We have limited information on why citation data was not available for the remaining observations (we refer to this as the missing sub-sample). There is a possibility that the authors changed the title of the eventually published piece, which our automated data collection could not pick up. Just by looking at a random sample of 50 papers from the missing observations, this does not appear to be a major problem. What could be more of an issue is that those presentation titles that were not found on Microsoft Academic could constitute papers that, either were never published (not even as working papers), or were so obscure that Microsoft did not list them. In both cases it would mean that our sub-sample of analysed presentations had, on average, more citations than those where our automated data collection did not provide us with a citation number. To verify, we looked at a random sample of 50 presentations from the missing sub-sample. After manually searching for each article using Google, we found information on 37 of them. These were dominantly working papers and conference proceedings, and on average had 9.7 citations. This is significantly less than the same figure for the scraped sample (26.3 citations).

Regarding the other characteristics of the missing sub-sample, Table 17 in the Appendix shows the average values of our observed features for the two sub-samples: where we were able to collect citation data, and where this was not possible. It appears that the observable features of the two samples are very similar.

So what do the above findings imply about the missing observations? For the sub-sample where data was available, it took around $2300 \mathrm{~km}$ of conference travelling for each extra citation. European speakers were most efficient in this, requiring only around $1500 \mathrm{~km}$ for each citation, followed by US speakers (around $2200 \mathrm{~km}$ ) and finally speakers from other regions (around $3900 \mathrm{~km}$ ). For the missing sub-sample these figures must be higher, because the average travel distance is very similar for both sub-samples, but citation

\footnotetext{
${ }^{24}$ For papers that use citation numbers or related bibliometric data in evaluating academic conference-going and mobility see for example: de Leon and McQuillin (2020), Sugimoto et al. (2017), Adams (2013), Wynes et al. (2019), or Derudder and Liu (2016).
} 
number is likely to be lower for the missing sub-sample. Therefore, if anything, the missing part of our sample is likely to consists of papers associated with even higher per-citation carbon emission levels.

Finally, with regards to our finding on the relative role of the number of trips and the distance travelled in driving citations, we do not have much evidence on how this would hold up for other samples or for the missing sub-sample. For the above mentioned 50 randomly selected presentations, the correlation between distance travelled and number of citations is close to zero - which would partially confirm our findings above, but the size of this verification sample was not sufficiently large to replicate the full regression analysis above.

\section{Concluding thoughts and policy recommendations}

This paper provided a detailed analysis of the travelling behaviour of academics in economics. We believe the descriptive numbers alone already deserve attention. But the paper also provides evidence and support for some increasingly popular policy suggestions to reduce the carbon impact of academic work. Below we list a number of these recommendations.

- Researchers could be encouraged to focus on local conference presentations instead of long distance ones. This could help reduce carbon emissions without much hindrance to the beneficial impact of these conferences (if measured by citation numbers). If the total distance travelled had been halved by cutting out long-distance trips, it could have lead to a 25,000 metric tonne reduction in carbon emission just from these 263 conferences (using average emission figures, as presented above). Of course, doing mainly local/regional presentations might lead to inequalities: for example, someone in the northeast of the US, or in California might not suffer from doing only local presentations, but someone in New Zealand might. Although our results, regarding speakers from regions other than North America and Europe, do not suggest that this would be a big problem - at least when the number of citations is used as a quality benchmark.

- More consideration could be given to virtual conferences. Online conferences can be thought of as very short-trip conferences (with zero mileage). Although online conferences had been predicted an important role in academia, it took a long time and a global pandemic to approach the same stature as physical conferences in social sciences. Organising virtual conferences is not without any challenge Carr and Ludvigsen (2017). A detailed comparison of the pros and cons of virtual conferences for 
different conference models is given in Sá et al. (2019). Regarding the relative advantages, virtual conferences can facilitate participation, and reduce inequalities Hanson et al. (2018) and provide access for remote, resource-limited researchers, particularly those from developing countries Fraser et al. (2017). Also, learning, one of the main objectives of academic conferences can be equally (and in some cases more efficiently) achieved in a virtual setting Sköld (2012). On the other hand, other aspects of online conferences pose more challenges. For example the networking function of conferences is still perceived by many to be more efficiently delivered in physical settings. However, the more inclusive nature of virtual conferences can contribute to other aspects of networking, provided that well-designed virtual interaction rooms are set up and participants are able to use them. With the increase in the accessibility of these video conferencing solutions, preferences are also likely to soften. Denstadli et al. (2012) report the results of a survey, in which respondents expressed a belief in the travel replacement capacity of video conferences. Among the more nuanced results they report that respondents who had access to in-house videoconferencing rooms were more likely to believe in substitution between travel and video conferences.

- Conference organisers could publish the estimated total carbon impact of travelling to the conference. This information is easily accessible for the organisers when the speakers register. At the very minimum conferences should disclose rough estimates based on the home institution of the speaker. This paper demonstrated an easily executable way to gather such evidence on conference carbon footprints.

- Universities could keep track of the conference related carbon footprint of their staff. This could include simply disclosing staff-mileage, but also initiatives such as preference for travel-free meetings, ground-travel, or extensive stays. Moreover, they could keep tabs of how the papers presented on longer trips perform in terms of citations.

- Academic associations could change the way their annual conferences are organised. This could include biannual (instead of annual) conferences. Some authors suggest decentralising larger conferences (Hischier and Hilty, 2002). Wenner et al. (2019) offer some experimentation across three dimensions (centralised - dispersed, single-venue - multi-venue, rotating - non-rotating), and point out the economic benefits of a single venue centralised large-scale event. However, a rotating multivenue format with centralised secondary venues seems most promising in delivering the most sustainable outcomes. Although Orsi (2012) pointed out that in this case the benefits from a drop in 
distance travelled might be cancelled out by the increase in the number of people travelling. For this reason Orsi (2012) suggest a sequential approach: first processing applications as a single-event, and then allocating each based on distance.

Although the above recommendations flow directly from the results of this paper, for real change, academics in general need a complete shift in their attitudes (Higham and Font, 2020), and in their own conventions regarding conferences. This is a much harder objective but a number of roadmaps have been proposed (Le Quéré et al., 2015, Bossdorf et al., 2010). Moreover, we also hope that papers, similar to this current one can contribute to raising awareness of the importance of change.

Focusing on economics, in the future it would be interesting to look at the carbon impact of publishing in the top journals. Getting the paper out, making sure the editor is already familiar with the work by the time they receive a manuscript, is an important part of the publication game. But this requires intensive travelling and presentations, and one might wonder how much of these increased social costs only serve limited private benefits (to have a paper accepted in a better journal). It is difficult to see how travelling patters would change without changing the way research is published.

\section{Appendix}

Tables and figures, that are referenced but not displayed in the main text are shown below. 
Table 11: Summary statistics - presentation level

\begin{tabular}{lllllllll}
\hline & count & mean & std & min & $\mathbf{2 5 \%}$ & $\mathbf{5 0 \%}$ & $\mathbf{7 5 \%}$ & max \\
\hline Conference size & 55005 & 398.72 & 341.93 & 3 & 191 & 306 & 432 & 1391 \\
Year & 55006 & 2012.98 & 4.48 & 2001 & 2009 & 2015 & 2016 & 2018 \\
Distance & 55006 & 7.52 & 7.92 & 0 & 1.21 & 3.54 & 12.82 & 39.01 \\
Speaker (Europe) & 55006 & 0.37 & 0.48 & 0 & 0 & 0 & 1 & 1 \\
Speaker (North America) & 55006 & 0.42 & 0.49 & 0 & 0 & 0 & 1 & 1 \\
Speaker (Asia-Pacific) & 55006 & 0.08 & 0.27 & 0 & 0 & 0 & 0 & 1 \\
Speaker (Latin America) & 55006 & 0.02 & 0.15 & 0 & 0 & 0 & 0 & 1 \\
Speaker (other) & 55006 & 0.12 & 0.32 & 0 & 0 & 0 & 0 & 1 \\
Venue (Europe) & 55006 & 0.45 & 0.5 & 0 & 0 & 0 & 1 & 1 \\
Venue (North America) & 55006 & 0.39 & 0.49 & 0 & 0 & 0 & 1 & 1 \\
Venue (Asia-Pacific) & 55006 & 0.1 & 0.3 & 0 & 0 & 0 & 0 & 1 \\
Venue (Latin America) & 55006 & 0.03 & 0.16 & 0 & 0 & 0 & 0 & 1 \\
Venue (other) & 55006 & 0.03 & 0.18 & 0 & 0 & 0 & 0 & 1 \\
Cross-Atlantic trip & 55006 & 0.19 & 0.39 & 0 & 0 & 0 & 0 & 1 \\
Total citations for paper presented & 31725 & 26.29 & 117.81 & 0 & 0 & 2 & 10 & 5869 \\
Speaker total citations & 31725 & 1476.17 & 5341.91 & 0 & 7 & 155.5 & 951 & 152748 \\
Speaker total publications & 31725 & 33.24 & 59.53 & 1 & 3 & 18 & 41 & 2124 \\
\hline
\end{tabular}

Table 12: Conference trips by country of the conference venue

\begin{tabular}{|c|c|c|c|c|c|c|c|}
\hline Venue country & $\begin{array}{l}\text { Average } \\
\text { distance } \\
\text { travelled } \\
(\mathbf{1 0 0 0} \mathbf{~ k m})\end{array}$ & $\begin{array}{l}\text { Number of } \\
\text { conferences }\end{array}$ & $\begin{array}{l}\text { Number of } \\
\text { trips }\end{array}$ & Venue country & $\begin{array}{l}\text { Average } \\
\text { distance } \\
\text { travelled } \\
(\mathbf{1 0 0 0} \mathbf{~ k m})\end{array}$ & $\begin{array}{l}\text { Number of } \\
\text { conferences }\end{array}$ & $\begin{array}{l}\text { Number of } \\
\text { trips }\end{array}$ \\
\hline Vietnam & 18.410 & 1 & 203 & Norway & 8.807 & 3 & 554 \\
\hline Argentina & 17.927 & 1 & 197 & Cote d'Ivoire & 7.853 & 1 & 76 \\
\hline South Korea & 17.681 & 3 & 746 & Portugal & 7.750 & 3 & 1932 \\
\hline Hong Kong & 16.235 & 1 & 128 & Brazil & 7.615 & 7 & 735 \\
\hline New Zealand & 15.808 & 2 & 210 & Denmark & 7.553 & 2 & 142 \\
\hline Australia & 15.243 & 13 & 2006 & Luxembourg & 7.546 & 1 & 306 \\
\hline Singapore & 14.127 & 3 & 487 & Sweden & 7.421 & 1 & 266 \\
\hline Japan & 13.144 & 4 & 928 & Canada & 7.370 & 11 & 4408 \\
\hline Hungary & 12.944 & 1 & 332 & Netherlands & 7.120 & 3 & 472 \\
\hline India & 12.692 & 1 & 125 & Mexico & 7.093 & 2 & 607 \\
\hline Czechia & 12.433 & 1 & 351 & Italy & 6.549 & 23 & 3588 \\
\hline Poland & 12.431 & 1 & 431 & United Kingdom & 6.195 & 31 & 6976 \\
\hline Turkey & 12.385 & 4 & 933 & Switzerland & 6.191 & 1 & 1254 \\
\hline Taiwan & 11.126 & 5 & 588 & Germany & 6.180 & 7 & 3326 \\
\hline Greece & 10.590 & 1 & 403 & United States & 5.922 & 88 & 17135 \\
\hline Chile & 10.323 & 6 & 524 & Belgium & 5.032 & 1 & 272 \\
\hline France & 10.290 & 4 & 774 & Spain & 4.231 & 20 & 3112 \\
\hline Panama & 9.769 & 1 & 177 & China & 3.427 & 1 & 1 \\
\hline Ireland & 8.911 & 2 & 221 & Austria & 1.449 & 1 & 48 \\
\hline
\end{tabular}

The table shows for each country, the number of conferences organised in the given country, the number of trips to these conferences, and the average distance of these trips. Rows are in decreasing order by the average distance travelled. A total of 263 conferences, 55,006 presentations, 26,312 speakers. 
Table 13: Conference trips by country of speaker

\begin{tabular}{|c|c|c|c|c|c|c|c|}
\hline $\begin{array}{l}\text { Speaker's coun- } \\
\text { try }\end{array}$ & $\begin{array}{l}\text { Average } \\
\text { distance } \\
\text { travelled } \\
(1000 \mathbf{~ k m})\end{array}$ & $\begin{array}{l}\text { Number of } \\
\text { conferences } \\
\text { attended }\end{array}$ & $\begin{array}{l}\text { Number } \\
\text { of trips }\end{array}$ & Speaker's country & $\begin{array}{l}\text { Average } \\
\text { distance } \\
\text { travelled } \\
(1000 \mathbf{~ k m})\end{array}$ & $\begin{array}{l}\text { Number of } \\
\text { conferences } \\
\text { attended }\end{array}$ & $\begin{array}{l}\text { Number } \\
\text { of trips }\end{array}$ \\
\hline South Africa & 19.561 & 39 & 144 & Portugal & 7.775 & 102 & 224 \\
\hline Hong Kong & 16.183 & 104 & 285 & Canada & 7.499 & 234 & 3010 \\
\hline New Zealand & 15.729 & 60 & 143 & Greece & 7.301 & 39 & 61 \\
\hline Singapore & 15.239 & 100 & 329 & Sweden & 7.023 & 142 & 520 \\
\hline Japan & 14.257 & 164 & 928 & Denmark & 6.868 & 128 & 367 \\
\hline Jerusalem & 14.230 & 32 & 53 & France & 6.349 & 200 & 1608 \\
\hline China & 13.429 & 40 & 70 & Netherlands & 5.773 & 172 & 1223 \\
\hline South Korea & 13.380 & 91 & 206 & Hungary & 5.755 & 53 & 103 \\
\hline Colombia & 13.092 & 57 & 87 & Ireland & 5.699 & 60 & 106 \\
\hline Australia & 13.016 & 173 & 1609 & Norway & 5.493 & 109 & 360 \\
\hline Israel & 12.885 & 67 & 143 & Switzerland & 5.493 & 172 & 840 \\
\hline India & 12.870 & 75 & 227 & Belgium & 5.409 & 144 & 532 \\
\hline Argentina & 11.693 & 26 & 50 & Germany & 5.203 & 217 & 3165 \\
\hline Taiwan & 11.456 & 87 & 328 & Czechia & 5.056 & 65 & 149 \\
\hline Cyprus & 10.015 & 36 & 54 & United Kingdom & 4.717 & 235 & 5294 \\
\hline Mexico & 9.932 & 117 & 405 & Poland & 4.694 & 45 & 88 \\
\hline Turkey & 9.768 & 91 & 249 & Luxembourg & 4.496 & 51 & 100 \\
\hline Chile & 8.560 & 79 & 348 & Austria & 4.341 & 97 & 317 \\
\hline Brazil & 8.192 & 93 & 734 & Spain & 3.749 & 184 & 2517 \\
\hline Finland & 8.175 & 90 & 191 & Italy & 3.462 & 197 & 2580 \\
\hline United States & 7.892 & 259 & 22973 & & & & \\
\hline
\end{tabular}

The table shows for each country, the total number of conferences attended by academics from the given country, the number of trips to these conferences, and the average distance of these trips. Rows are in decreasing order by the average distance travelled. A total of 263 conferences, 55,006 presentations, 26,312 speakers.

Table 14: Flying-related $\mathrm{CO}_{2}$ emission figures (metric tonnes) - by venue region

\begin{tabular}{|c|c|c|c|c|c|c|c|}
\hline & & All & North America & Europe & Asia-Pacific & Latin America & Other \\
\hline \multirow[t]{3}{*}{ Total } & Average & 49405.93 & 21764.27 & 11723.38 & 6959.37 & 1290.11 & 7668.8 \\
\hline & Optimistic & 34389.28 & 15149.15 & 8160.12 & 4844.11 & 897.99 & 5337.91 \\
\hline & Pessimistic & 78866.07 & 34742.04 & 18713.88 & 11109.16 & 2059.39 & 12241.6 \\
\hline \multirow[t]{6}{*}{ Per conference } & Average & 187.86 & 163.92 & 180.15 & 288.11 & 129.16 & 255.36 \\
\hline & & (196.53) & $(165.15)$ & (209.11) & (218.84) & $(131.81)$ & (252.7) \\
\hline & Optimistic & 130.76 & 114.1 & 125.39 & 200.54 & 89.91 & 177.74 \\
\hline & & (136.79) & (114.96) & (145.55) & (152.32) & (91.75) & (175.89) \\
\hline & Pessimistic & 299.87 & 261.66 & 287.57 & 459.9 & 206.18 & 407.63 \\
\hline & & (313.71) & $(263.63)$ & (333.8) & (349.33) & $(210.41)$ & (403.38) \\
\hline \multirow[t]{6}{*}{ Per trip } & Average & 0.9 & 0.75 & 0.78 & 1.81 & 1.24 & 1.26 \\
\hline & & $(0.98)$ & $(0.83)$ & $(0.86)$ & (1.4) & (1.1) & $(0.93)$ \\
\hline & Optimistic & 0.63 & 0.52 & 0.54 & 1.26 & 0.86 & 0.88 \\
\hline & & $(0.68)$ & $(0.58)$ & (0.6) & $(0.97)$ & $(0.77)$ & $(0.64)$ \\
\hline & Pessimistic & 1.43 & 1.2 & 1.24 & 2.88 & 1.98 & 2.01 \\
\hline & & (1.56) & (1.32) & (1.37) & $(2.23)$ & (1.76) & (1.48) \\
\hline
\end{tabular}

We assumed three scenarios, the greenest one, based on the best performing airline in the study $(75 \mathrm{~g}$ per passenger $\mathrm{km}$ expected by 2020), the least-green one, based on the worst performing airline (172 $\mathrm{g}$ per passenger km expected by 2020), and an average one at $107.75 \mathrm{~g}$, which was calculated as an average of the 19 airlines reported by Transition Pathway Initiative (TPI) - see footnote 8. 
Table 15: Flying-related $\mathrm{CO}_{2}$ emission figures (metric tonnes) - by speaker's home institution

\begin{tabular}{lllllll}
\hline & & North America & Europe & Asia-Pacific & Latin America & Other \\
\hline Total & Average & 21764.27 & 11723.38 & 6959.37 & 1290.11 & 7668.80 \\
& Optimistic & 15149.15 & 8160.12 & 4844.11 & 897.99 & 5337.91 \\
& Pessimistic & 34742.04 & 18713.88 & 11109.16 & 2059.39 & 12241.60 \\
\hline Per trip & Average & 0.95 & 0.58 & 1.63 & 1.05 & 1.21 \\
& & $(0.92)$ & $(0.81)$ & $(1.38)$ & $(1.05)$ & $(0.93)$ \\
& Optimistic & 0.66 & 0.4 & 1.13 & 0.73 & 0.84 \\
& & $(0.64)$ & $(0.57)$ & $(0.96)$ & $(0.73)$ & $(0.65)$ \\
& Pessimistic & 1.51 & 0.93 & 2.6 & 1.67 & 1.92 \\
& & $(1.46)$ & $(1.3)$ & $(2.2)$ & $(1.68)$ & $(1.49)$ \\
\hline
\end{tabular}

Standard deviation in parentheses.

Figure 3: Regression tree

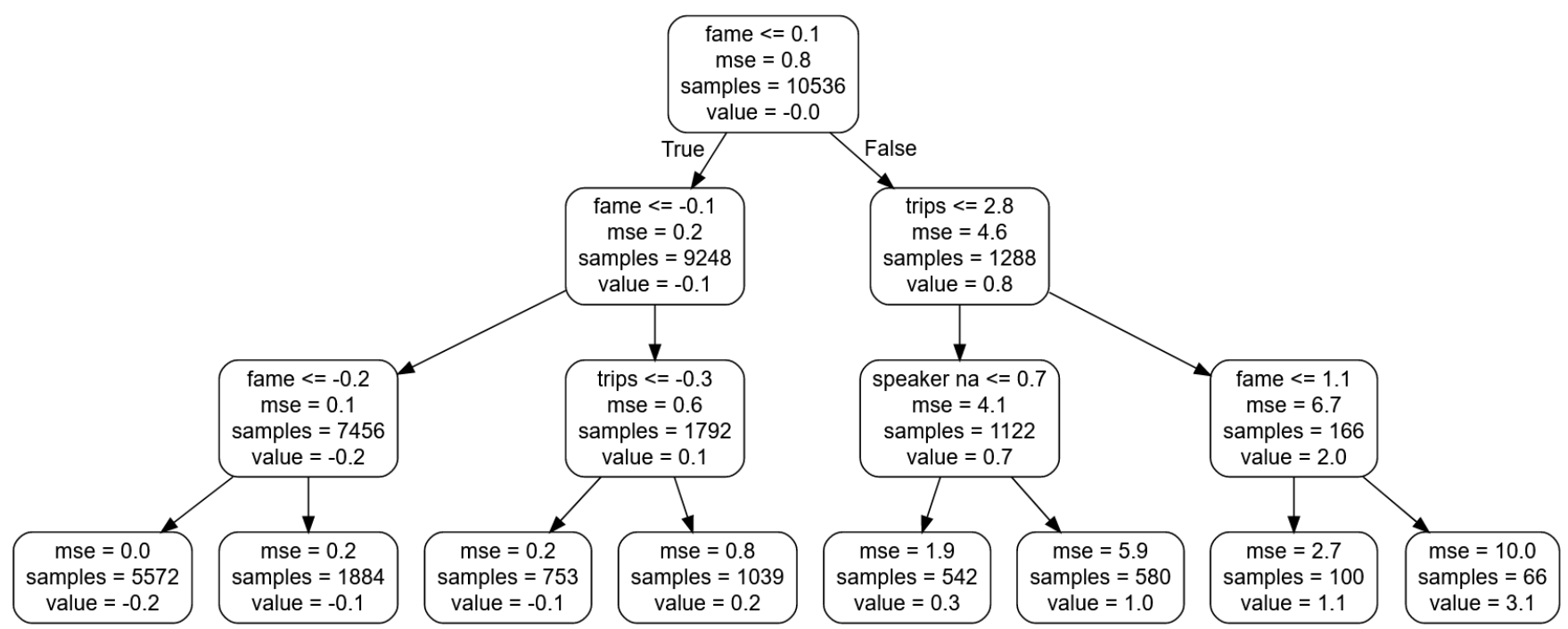

A tree consists of a root node (node 1), containing all observations. This node is split into branches and leaves (end nodes) based on the value of predictors. The regression tree algorithm does segment the predictor space into a number of regions and within each leaf it calculates the average predicted value and percentage of the training observations within that region. The variable that determines node 1 is the most important variable for the classification. 
Table 16: Citation results - full table

\begin{tabular}{|c|c|c|c|c|}
\hline & Model 1 & Model 2 & Model 3 & Model 4 \\
\hline distance & $\begin{array}{l}0.0204 * \\
(0.0111)\end{array}$ & $\begin{array}{l}0.0271 \text { *** } \\
(0.0100)\end{array}$ & $\begin{array}{l}-0.0032 \\
(0.0055)\end{array}$ & $\begin{array}{l}0.0029 \\
(0.0051)\end{array}$ \\
\hline trips & $\begin{array}{l}0.1288^{* * * *} \\
(0.0139)\end{array}$ & $\begin{array}{l}0.1494 * * * \\
(0.0159)\end{array}$ & $\begin{array}{l}0.2383^{* * * *} \\
(0.0137)\end{array}$ & $\begin{array}{l}0.2452^{* * *} \\
(0.0139)\end{array}$ \\
\hline fame & $\begin{array}{l}0.0686^{*} \\
(0.0393)\end{array}$ & & $\begin{array}{l}0.1922 * * * \\
(0.0308)\end{array}$ & $\begin{array}{l}0.1982^{* * * *} \\
(0.0315)\end{array}$ \\
\hline distance $\mathrm{x}$ fame & $\begin{array}{l}-0.0617^{*} \\
(0.0367)\end{array}$ & & & \\
\hline trips $x$ fame & $\begin{array}{l}0.0363 \\
(0.0287)\end{array}$ & & & \\
\hline conference size & $\begin{array}{l}-0.0131 * * * \\
(0.0049)\end{array}$ & $\begin{array}{l}-0.0113 * * \\
(0.0049)\end{array}$ & $\begin{array}{l}-0.0157 * * * \\
(0.0048)\end{array}$ & \\
\hline distance $x$ speaker(Asia-Pacific) & $\begin{array}{l}-0.0253^{*} \\
(0.0132)\end{array}$ & $\begin{array}{l}-0.0274 * * \\
(0.0116)\end{array}$ & & \\
\hline distance $x$ speaker(Asia-Pacific) $x$ fame & $\begin{array}{l}0.0274 \\
(0.0413)\end{array}$ & & & \\
\hline distance $x$ speaker(Latin America) & $\begin{array}{l}0.0092 \\
(0.0708)\end{array}$ & $\begin{array}{l}-0.0170 \\
(0.0133)\end{array}$ & & \\
\hline distance $x$ speaker(Latin America) $x$ fame & $\begin{array}{l}0.1702 \\
(0.3707)\end{array}$ & & & \\
\hline distance $x$ speaker(other) & $\begin{array}{l}0.0027 \\
(0.0217)\end{array}$ & $\begin{array}{l}-0.0242 * \\
(0.0146)\end{array}$ & & \\
\hline distance $x$ speaker(other) $x$ fame & $\begin{array}{l}0.2056 * * \\
(0.0903)\end{array}$ & & & \\
\hline distance x speaker(North America) & $\begin{array}{l}-0.0319^{* *} \\
(0.0159)\end{array}$ & $\begin{array}{l}-0.0334 * * \\
(0.0150)\end{array}$ & & \\
\hline distance $x$ speaker(North America) $x$ fame & $\begin{array}{l}0.0716 \\
(0.0618)\end{array}$ & & & \\
\hline trips $x$ speaker(Asia-Pacific) & $\begin{array}{l}-0.0638^{* * * *} \\
(0.0233)\end{array}$ & $\begin{array}{l}-0.0781 * * * \\
(0.0254)\end{array}$ & & \\
\hline trips $x$ speaker(Asia-Pacific) $x$ fame & $\begin{array}{l}-0.0218 \\
(0.0381)\end{array}$ & & & \\
\hline trips $x$ speaker(Latin America) & $\begin{array}{l}-0.1394^{*} \\
(0.0739)\end{array}$ & $\begin{array}{l}-0.0961^{* * * *} \\
(0.0285)\end{array}$ & & \\
\hline trips $x$ speaker(Latin America) $x$ fame & $\begin{array}{l}-0.3212 \\
(0.3973)\end{array}$ & & & \\
\hline trips $\mathrm{x}$ speaker(other) & $\begin{array}{l}0.0531 \\
(0.0347)\end{array}$ & $\begin{array}{l}0.0571 \\
(0.0465)\end{array}$ & & \\
\hline trips $x$ speaker(other) $x$ fame & $\begin{array}{l}-0.0105 \\
(0.1004)\end{array}$ & & & \\
\hline trips x speaker(North America) & $\begin{array}{l}0.2001 * * * \\
(0.0307)\end{array}$ & $\begin{array}{l}0.2441 * * * \\
(0.0316)\end{array}$ & & \\
\hline trips $x$ speaker(North America) $x$ fame & $\begin{array}{l}-0.0433 \\
(0.0427)\end{array}$ & & & \\
\hline speaker(Asia-Pacific) & $\begin{array}{l}-0.0744 * * * \\
(0.0191)\end{array}$ & $\begin{array}{l}-0.0839 * * * \\
(0.0166)\end{array}$ & $\begin{array}{l}-0.0306^{* *} \\
(0.0142)\end{array}$ & \\
\hline speaker(Asia-Pacific) $\mathrm{x}$ fame & $\begin{array}{l}0.0071 \\
(0.0498)\end{array}$ & & & \\
\hline speaker(Latin America) & $\begin{array}{l}0.0763 \\
(0.2144)\end{array}$ & $\begin{array}{l}-0.1060 * * * \\
(0.0232)\end{array}$ & $\begin{array}{l}-0.0522 * * \\
(0.0228)\end{array}$ & \\
\hline speaker(Latin America) $x$ fame & $\begin{array}{l}0.9254 \\
(1.0694)\end{array}$ & & & \\
\hline speaker(other) & $\begin{array}{l}0.0038 \\
(0.0238)\end{array}$ & $\begin{array}{l}-0.0087 \\
(0.0190)\end{array}$ & $\begin{array}{l}0.0155 \\
(0.0144)\end{array}$ & \\
\hline speaker(other) $x$ fame & $\begin{array}{l}0.0592 \\
(0.0835)\end{array}$ & & & \\
\hline speaker(North America) & $\begin{array}{l}0.2061 * * * \\
(0.0207)\end{array}$ & $\begin{array}{l}0.2197 * * * \\
(0.0191)\end{array}$ & $\begin{array}{l}0.2017 \text { *** } \\
(0.0178)\end{array}$ & \\
\hline speaker(North America) x fame & $\begin{array}{l}0.1782 * * \\
(0.0794)\end{array}$ & & & \\
\hline Intercept & $\begin{array}{l}-0.0856^{* * * *} \\
(0.0108)\end{array}$ & $\begin{array}{l}-0.0835 * * * \\
(0.0090)\end{array}$ & $\begin{array}{l}-0.0771 * * * \\
(0.0084)\end{array}$ & $\begin{array}{l}0.0000 \\
(0.0073)\end{array}$ \\
\hline $\mathbf{N}$ & 16625 & 16625 & 16625 & 16625 \\
\hline $\mathbf{R 2}$ & 0.15 & 0.11 & 0.13 & 0.12 \\
\hline
\end{tabular}

Standard errors in parentheses.

$* \mathrm{p}<.1, * * \mathrm{p}<.05, * * * \mathrm{p}<.01$ 
Table 17: Comparing samples where citation was scraped with those where it was not (speaker-level averages)

\begin{tabular}{lcc}
\hline & citation collected & citation not collected \\
\hline distance & 7.434 & 7.444 \\
& $(7.217)$ & $(7.732)$ \\
co2_average & 0.894 & 0.882 \\
& $(0.902)$ & $(0.95)$ \\
number of trips & 1.908 & 1.465 \\
& $(1.622)$ & $(0.959)$ \\
year & 2012.615 & 2013.576 \\
& $(4.316)$ & $(4.048)$ \\
conference_size & 404.089 & 367.81 \\
& $(308.686)$ & $(302.761)$ \\
venue_eur & 0.465 & 0.429 \\
& $(0.455)$ & $(0.469)$ \\
speaker_eur & 0.389 & 0.345 \\
& $(0.477)$ & $(0.469)$ \\
venue_na & 0.37 & 0.378 \\
& $(0.438)$ & $(0.459)$ \\
speaker_na & 0.392 & 0.395 \\
& $(0.475)$ & $(0.481)$ \\
venue_ap & 0.11 & 0.116 \\
& $(0.289)$ & $(0.307)$ \\
speaker_ap & 0.083 & 0.093 \\
& $(0.271)$ & $(0.288)$ \\
venue_la & 0.026 & 0.037 \\
& $(0.152)$ & $(0.182)$ \\
speaker_la & 0.022 & 0.027 \\
& $(0.145)$ & $(0.159)$ \\
venue_other & 0.029 & 0.04 \\
& $(0.145)$ & $(0.185)$ \\
speaker_other & 0.114 & 0.141 \\
& $(0.308)$ & $(0.342)$ \\
\hline Stan &
\end{tabular}

Standard deviation in parentheses 
Table 18: Ridge regressions with different $\alpha$ levels and the linear regression coefficients

\begin{tabular}{lccc}
\hline & linear & ridge & ridge \\
& & $(\alpha=0.01)$ & $(\alpha=100)$ \\
\hline distance & 0.0545 & 0.0204 & 0.0193 \\
trips & 0.1367 & 0.1288 & 0.1297 \\
fame & 0.0797 & 0.0686 & 0.0757 \\
conference size & -0.0161 & -0.0131 & -0.0127 \\
speaker na & 0.1186 & 0.2061 & 0.2016 \\
speaker_ap & -0.1627 & -0.0744 & -0.0666 \\
speaker_la & -0.0123 & 0.0753 & -0.0648 \\
speaker_other & -0.0843 & 0.0038 & -0.0017 \\
(distance) x (na speaker) & -0.0660 & -0.0319 & -0.0300 \\
(distance) x (ap speaker) & -0.0588 & -0.0253 & -0.0260 \\
(distance) x (la speaker) & -0.0228 & 0.0093 & -0.0160 \\
(distance) x (other speaker) & -0.0316 & 0.0027 & -0.0037 \\
(trips) x (na speaker) & 0.1909 & 0.2001 & 0.1965 \\
(trips) x (ap speaker) & -0.0739 & -0.0638 & -0.0530 \\
(trips) x (la speaker) & -0.1491 & -0.1391 & -0.0495 \\
(trips) x (other speaker) & 0.0417 & 0.0531 & 0.0516 \\
(dist) x (fame) & -0.0643 & -0.0617 & -0.0509 \\
(trips) x (fame) & 0.0223 & 0.0363 & 0.0327 \\
(fame) x (na speaker) & 0.1662 & 0.1782 & 0.1668 \\
(fame) x (ap speaker) & -0.0037 & 0.0071 & 0.0034 \\
(fame) x (la speaker) & 0.9139 & 0.9199 & 0.0306 \\
(fame) x (other speaker) & 0.0481 & 0.0592 & 0.0221 \\
(distance) x (na speaker) x (fame) & 0.0742 & 0.0716 & 0.0590 \\
(distance) x (ap speaker) x (fame) & 0.0297 & 0.0274 & 0.0145 \\
(distance) x (la speaker) x (fame) & 0.1771 & 0.1711 & 0.0177 \\
(distance) x (other speaker) x (fame) & 0.2085 & 0.2056 & 0.1417 \\
(trips) x (na speaker) x (fame) & -0.0288 & -0.0433 & -0.0381 \\
(trips) x (ap speaker) x (fame) & -0.0073 & -0.0218 & -0.0135 \\
(trips) x (la speaker) x (fame) & -0.3053 & -0.3195 & 0.0037 \\
(trips) x (other speaker) x (fame) & 0.0042 & -0.0105 & -0.0006 \\
\hline & & & \\
\hline
\end{tabular}




\section{References}

Achten, W. M., Almeida, J., and Muys, B. (2013). Carbon footprint of science: More than flying. Ecological indicators, 34:352-355.

Adams, J. (2013). Collaborations: The fourth age of research. Nature, 497(7451):557.

Arsenault, J., Talbot, J., Boustani, L., Gonzalès, R., and Manaugh, K. (2019). The environmental footprint of academic and student mobility in a large research-oriented university. Environmental Research Letters, 14(9):095001.

Attari, S. Z., Krantz, D. H., and Weber, E. U. (2016). Statements about climate researchers carbon footprints affect their credibility and the impact of their advice. Climatic Change, 138(1-2):325-338.

Balmford, A., Cole, L., Sandbrook, C., and Fisher, B. (2017). The environmental footprints of conservationists, economists and medics compared. Biological Conservation, 214:260-269.

Bossdorf, O., Parepa, M., and Fischer, M. (2010). Climate-neutral ecology conferences: just do it! Trends in ecology \& evolution, 25(2):61.

Burke, I. C. (2010). Travel trade-offs for scientists. Science, 330(6010):1476-1476.

Callister, M. E. and Griffiths, M. J. (2007). The carbon footprint of the american thoracic society meeting. American journal of respiratory and critical care medicine, 175(4):417-417.

Cantwell, J. A. and Mudambi, R. (2011). Physical attraction and the geography of knowledge sourcing in multinational enterprises. Global Strategy Journal, 1(3-4):206-232.

Carr, T. and Ludvigsen, S. R. (2017). Disturbances and contradictions in an online conference. International Journal of Education and Development using Information and Communication Technology, 13(2):116-140.

Ciers, J., Mandic, A., Toth, L., and Opt Veld, G. (2019). Carbon footprint of academic air travel: A case study in switzerland. Sustainability, 11(1):80.

de Leon, F. L. L. and McQuillin, B. (2020). The role of conferences on the pathway to academic impact evidence from a natural experiment. Journal of Human Resources, 55(1):164-193. 
Denstadli, J. M., Julsrud, T. E., and Hjorthol, R. J. (2012). Videoconferencing as a mode of communication: A comparative study of the use of videoconferencing and face-to-face meetings. Journal of Business and Technical Communication, 26(1):65-91.

Derudder, B. and Liu, X. (2016). How international is the annual meeting of the association of american geographers? a social network analysis perspective. Environment and Planning A, 48(2):309-329.

Desiere, S. (2016). The carbon footprint of academic conferences: Evidence from the 14th eaae congress in slovenia. EuroChoices, 15(2):56-61.

Edler, J., Fier, H., and Grimpe, C. (2011). International scientist mobility and the locus of knowledge and technology transfer. Research policy, 40(6):791-805.

Elliott, A. and Urry, J. (2010). Mobile lives. Routledge.

Fox, H. E., Kareiva, P., Silliman, B., Hitt, J., Lytle, D. A., Halpern, B. S., Hawkes, C. V., Lawler, J., Neel, M., Olden, J. D., et al. (2009). Why do we fly? ecologists' sins of emission. Frontiers in Ecology and the Environment, 7(6):294-296.

Fraser, H., Soanes, K., Jones, S. A., Jones, C. S., and Malishev, M. (2017). The value of virtual conferencing for ecology and conservation. Conservation Biology, 31(3):540-546.

Gössling, S., Hanna, P., Higham, J., Cohen, S., and Hopkins, D. (2019). Can we fly less? evaluating the 'necessity’ of air travel. Journal of Air Transport Management, 81:101722.

Green, M. (2008). Are international medical conferences an outdated luxury the planet can't afford? yes. Bmj, 336(7659):1466-1466.

Hanson, S. L., Sykes, M., and Pena, L. B. (2018). Gender equity in science: The global context. Int'l J. Soc. Sci. Stud., 6:33.

Higham, J. and Font, X. (2020). Decarbonising academia: confronting our climate hypocrisy. Journal of Sustainable Tourism, 28(1):1-9.

Hischier, R. and Hilty, L. (2002). Environmental impacts of an international conference. Environmental Impact Assessment Review, 22(5):543-557.

Holden, M. H., Butt, N., Chauvenet, A., Plein, M., Stringer, M., and Chadès, I. (2017). Academic conferences urgently need environmental policies. Nature Ecology and Evolution, 1(9):1211-1212. 
Le Quéré, C., Capstick, S., Corner, A., Cutting, D., Johnson, M., Minns, A., Schroeder, H., WalkerSpringett, K., Whitmarsh, L., and Wood, R. (2015). Towards a culture of low-carbon research for the 21st century. Tyndall Centre for Climate Change Research, Working Paper, 161.

Leydesdorff, L., Bornmann, L., Comins, J. A., and Milojević, S. (2016). Citations: Indicators of quality? the impact fallacy. Frontiers in Research metrics and Analytics, 1:1.

Nevins, J. (2014). Academic jet-setting in a time of climate destabilization: Ecological privilege and professional geographic travel. The Professional Geographer, 66(2):298-310.

Orsi, F. (2012). Cutting the carbon emission of international conferences: is decentralization an option? Journal of Transport Geography, 24(C):462-466.

Sá, M. J., Ferreira, C. M., and Serpa, S. (2019). Virtual and face-to-face academic conferences: Comparison and potentials. Journal of Educational and Social Research, 9(2):35.

Sköld, O. (2012). The effects of virtual space on learning: A literature review. First Monday, 17(1).

Spinellis, D. and Louridas, P. (2013). The carbon footprint of conference papers. PloS one, 8(6).

Storme, T., Beaverstock, J. V., Derrudder, B., Faulconbridge, J. R., and Witlox, F. (2013). How to cope with mobility expectations in academia: Individual travel strategies of tenured academics at ghent university, flanders. Research in Transportation Business \& Management, 9:12-20.

Storme, T., Faulconbridge, J. R., Beaverstock, J. V., Derudder, B., and Witlox, F. (2017). Mobility and professional networks in academia: An exploration of the obligations of presence. Mobilities, 12(3):405424.

Stroud, J. T. and Feeley, K. J. (2015). Responsible academia: optimizing conference locations to minimize greenhouse gas emissions. Ecography, 38(4):402-404.

Sugimoto, C. R., Robinson-García, N., Murray, D. S., Yegros-Yegros, A., Costas, R., and Larivière, V. (2017). Scientists have most impact when they're free to move. Nature News, 550(7674):29.

Wang, W., Bai, X., Xia, F., Bekele, T. M., Su, X., and Tolba, A. (2017). From triadic closure to conference closure: The role of academic conferences in promoting scientific collaborations. Scientometrics, 113(1):177-193. 
Wenner, F., Caset, F., and De Wit, B. (2019). Conference locations and sustainability aspirations: Towards an integrative framework? disP-The Planning Review, 55(1):34-51.

Wynes, S., Donner, S. D., Tannason, S., and Nabors, N. (2019). Academic air travel has a limited influence on professional success. Journal of cleaner production, 226:959-967. 